\title{
REALIDADE E VALORES DE VERDADE NO TRACTATUS DE WITTGENSTEIN: UMA DEFESA DE UMA CONCEPÇÃO REALISTA DOS OBJETOS*
}

\author{
Reality and truth values in Wittgenstein's Tractatus: a defense of a realist conception of the
}

objects

Fernando Sposito Yokoyama**

\begin{abstract}
Resumo: No Tractatus Logico-Philosophicus de Wittgenstein, os sentidos proposicionais são explicados por meio de uma teoria da representação. Isso porque, nesta obra, Wittgenstein sustenta que uma proposição expressa um sentido na medida em que ela representa uma situação na realidade. Segundo a leitura denominada realista, a teoria tractariana da representação inclui a postulação de objetos simples que seriam, em um certo sentido, independentes da linguagem. Pode-se dizer, então, que essa leitura defende uma concepção realista dos objetos do Tractatus e atribui à obra teses que enunciariam as propriedades últimas de um domínio real independente. Já os proponentes da leitura denominada antirrealista recusam uma concepção realista dos objetos e, por conseguinte, recusam que o Tractatus contenha teses acerca de um domínio real independente, pois eles sustentam que essas teses dizem respeito apenas à ordem lógica dos nossos sistemas de representação preservada na realidade representada. Essas duas leituras baseiam suas posições em suas respectivas interpretações acerca do modo como, segundo o Tractatus, os sentidos proposicionais são estabelecidos. Neste artigo, pretendo mostrar que, embora essas duas interpretações acerca dos mecanismos de determinação do sentido proposicional encontrem apoio textual, a resposta para a questão de se o Tractatus possui, ou não, uma concepção realista dos objetos e teses acerca de um domínio real independente não depende de qual delas é a correta. Isso porque apenas em uma leitura realista é possível explicar a possibilidade de um valor de verdade para as proposições.
\end{abstract}

Palavras-chave: Tractatus. LogicoPhilosophicus. Ontologia. Valor de Verdade.

\begin{abstract}
In Wittgenstein's Tractatus LogicoPhilosophicus, the sense of the propositions are explained by means of a theory of representation. This is because Wittgenstein maintains in this work that a proposition expresses a sense insofar as it represents a situation in reality. According to the so-called realist reading, the tractarian theory of representation includes the postulation of simple objects that would be, in a certain sense, independent of language. One can say, then, that this reading supports a realist conception of the objects of the Tractatus, and ascribes to it theses that would state the ultimate properties of an independent reality. On the other hand, the proponents of the so-called anti-realist reading refuse a realist conception of the objects and, accordingly, refuse that the Tractatus contains thesis about an independent reality, for they maintain that these theses concern only the logical order of our systems of representation preserved in the reality that is represented. These two readings support their positions on the basis of their respective interpretations of the way in which, according to the Tractatus, the senses of the propositions are established. In this paper, I try to show that, although these two interpretations about the mechanisms of determining propositional senses have textual support, the answer to the question about whether the Tractatus contains, or not, a realist conception of the objects and thesis about an independent reality does not depend on which one is correct. This is because only on a realist reading it is possible to explain the possibility of a truth value for the propositions.
\end{abstract}

Keywords: Tractatus. Logico-Philosophicus. Ontology. Truth Values.

\footnotetext{
* Este artigo é uma extensão da dissertação de Mestrado do autor.

** Doutorando no Programa de Pós-graduação em Filosofia pela Universidade de São Paulo (USP). Bolsista CNPq. Contato: fernando_sy89@hotmail.com

\begin{tabular}{|c|c|c|c|c|c|}
\hline intuitio & $\begin{array}{c}\text { ISSN } \\
1983-4012\end{array}$ & Porto Alegre & Vol.7 - No.2 & $\begin{array}{c}\text { Novembro } \\
2014\end{array}$ & p. 51-72 \\
\hline
\end{tabular}
}




\section{Introdução}

O Tractatus Logico-Philosophicus ${ }^{1}$ inicia-se com uma série de enunciados através dos quais Wittgenstein caracteriza aquelas que seriam as propriedades essenciais e imutáveis da realidade. Segundo a interpretação mais tradicional da obra, esses enunciados estariam delineando teses acerca das propriedades últimas de uma realidade que deve ser concebida, em um sentido que será mais bem explicado, como anterior e independente da linguagem. Isso se deve, sobretudo, ao fato de que essa leitura defende uma concepção realista dos objetos simples postulados, por Wittgenstein, como os referentes dos nomes. Seguindo a prática mais ou menos estabelecida, denominaremos essa linha interpretativa "realista". Cumpre observar que, embora essa linha interpretativa seja caracterizada pela ideia de que o Tractatus contém teses acerca de uma realidade concebida como independente da linguagem, seus proponentes admitem que Wittgenstein as teria deduzido a partir de suas investigações acerca da essência da linguagem e da possibilidade do sentido proposicional. As investigações de Wittgenstein, acerca da forma essencial da linguagem, teriam mostrado que, para que a linguagem seja possível, a realidade, por ela descrita, deve possuir determinadas propriedades. Mas, segundo os proponentes dessa linha interpretativa, uma vez deduzidas tais propriedades estaríamos autorizados a considerá-las como pertencendo à realidade independentemente da linguagem a partir da qual elas foram deduzidas.

Essa interpretação mais tradicional é recusada pelos proponentes da leitura que podemos denominar "antirrealista". A marca distintiva, dessa segunda linha interpretativa, está na recusa de uma concepção realista dos objetos e, por conseguinte, na recusa de que o Tractatus contenha teses acerca de uma realidade concebida como independente da linguagem. Assim como os intérpretes realistas, os proponentes da leitura antirrealista sustentam que, no Tractatus, Wittgenstein realiza uma investigação acerca da possibilidade do sentido proposicional. No entanto, segundo eles, essa é uma investigação que jamais teria ultrapassado os limites da linguagem. Todas as teses do Tractatus, que supostamente postulam objetos simples independentes da linguagem e que, de modo geral, tratam das propriedades essenciais de uma realidade independente, diriam respeito exclusivamente à ordem lógica essencial dos nossos sistemas simbólicos preservada na realidade representada: a ordem lógica essencial da linguagem teria sido, portanto, o começo e o fim de todas as investigações de Wittgenstein.

Pretendo mostrar que a principal razão pela qual os proponentes dessas leituras opostas são levados a sustentar suas respectivas posições está na maneira pela qual eles concebem os mecanismos da teoria tractariana acerca do funcionamento da linguagem. Mais especificamente, eles são levados às suas respectivas posições devido as suas interpretações distintas acerca do modo pelo qual, segundo o

\footnotetext{
${ }^{1}$ As passagens do Tractatus serão referidas pela numeração dos aforismos. Foi utilizada a edição bilíngüe com tradução de Luiz Henrique Lopes dos Santos (WITTGENSTEIN, L. Tractatus Logico-Philosophicus. Trad., notas e ensaio introdutório de Luiz Henrique Lopes dos Santos. 3. ed. São Paulo: Edusp, 2001).

\begin{tabular}{|c|c|l|l|c|c|}
\hline intuitio & $\begin{array}{c}\text { ISSN } \\
1983-4012\end{array}$ & Porto Alegre & Vol.7- No.2 & $\begin{array}{c}\text { Novembro } \\
2014\end{array}$ & p. 51-72 \\
\hline
\end{tabular}
}


Tractatus, os sentidos das proposições são estabelecidos. Veremos que os intérpretes realistas sustentam que a teoria tractariana da linguagem pressupõe a realização de correlações singulares entre nomes e objetos externos. Já os proponentes da leitura antirrealista recusam essa concepção. Eles sustentam que, segundo Wittgenstein, tais correlações não são possíveis e que a teoria tractariana do sentido proposicional dá primazia ao uso dos nomes no contexto das proposições e no interior da linguagem.

Admitindo, por ora, que as leituras realista e antirrealista estão apoiadas em suas respectivas interpretações acerca do modo pelo qual, segundo o Tractatus, os significados dos nomes são identificados e os sentidos proposicionais estabelecidos, penso que devemos concluir que ambas encontram algum apoio textual. Pois, como veremos mais à frente, é possível encontrar no Tractatus tanto passagens que parecem favorecer a tese de que os sentidos proposicionais são estabelecidos mediante correlações singulares entre nomes e objetos externos, como passagens que parecem favorecer a tese de que a teoria tractariana do sentido proposicional dá primazia ao uso dos nomes no interior da linguagem. Sendo assim, pretendo, neste artigo, abordar o debate entre essas linhas interpretativas a partir de uma perspectiva diferente da que tem sido tomada pelos autores envolvidos neste debate. Enquanto esses autores baseiam suas posições em suas respectivas interpretações acerca do modo pelo qual os sentidos proposicionais são estabelecidos, penso que a questão de se o Tractatus possui, ou não, teses acerca das propriedades essenciais de um domínio real independente pode ser resolvida com base na questão acerca de qual destas linhas interpretativas é capaz de explicar, não o sentido, mas o valor de verdade das proposições. Deste modo, defenderei uma leitura realista da obra pelo fato de que, independentemente de questões referente aos mecanismos de determinação do sentido proposicional, em uma leitura antirrealista não se pode garantir que, para cada proposição, corresponda, na realidade, uma situação cuja existência ou inexistência a verifica ou falsifica. Enquanto ambas as interpretações acerca da possibilidade do sentido encontram algum apoio textual, penso que a questão referente à possibilidade do valor de verdade das proposições levanta problemas insuperáveis para a leitura antirrealista, de modo que teríamos, então, que rejeitá-la em favor da leitura rival. Esta será, segundo é do meu conhecimento, uma abordagem original do problema envolvido no debate entre essas leituras opostas.

Antes de prosseguir essa discussão, gostaria de reiterar o que entendo por uma "concepção realista dos objetos", já que esta noção estará no centro de toda a exposição que segue. Ao defender uma concepção realista dos objetos, estarei sustentando que os objetos simples, postulados por Wittgenstein, como os referentes dos nomes indefiníveis do Tractatus, são entidades que possuem uma certa independência com relação à linguagem, no sentido de que sua existência e sua identidade não seriam, tal como é defendido em uma leitura antirrealista da obra, determinadas ou impostas pelo uso de seus nomes. Deste modo, as teses tractarianas que postulam a existência de tais objetos e lhes atribuem possibilidades combinatórias fixas e imutáveis não diriam respeito apenas à ordem lógica da

\begin{tabular}{|c|c|l|l|c|c|}
\hline intuitio & $\begin{array}{c}\text { ISSN } \\
1983-4012\end{array}$ & Porto Alegre & Vol.7 $-\mathrm{N}^{\circ} .2$ & $\begin{array}{c}\text { Novembro } \\
2014\end{array}$ & p. 51-72 \\
\hline
\end{tabular}


linguagem preservada na realidade representada, mas estariam, sim, tratando das propriedades últimas e essenciais de um domínio real exterior e independente.

\section{A leitura realista apoiada no apelo a correlações singulares entre nomes e objetos externos}

Um melhor entendimento da abordagem que será dada a esse problema exigirá uma apresentação das linhas gerais ao longo das quais essa discussão foi conduzida até então. Vimos que o ponto de partida, comum às leituras realista e antirrealista, é o de que o Tractatus contém teses acerca da possibilidade do sentido proposicional. É também consenso entre elas que a abordagem desse tema, no plano da obra, ganha a forma de uma investigação acerca da natureza essencial da representação. Isso porque, no Tractatus, dizer que uma proposição expressa um sentido é o mesmo que dizer que ela enuncia a existência ou inexistência de uma determinada situação na realidade. Portanto, explicar a possibilidade do sentido proposicional é explicar como pode uma proposição apontar para fora de si mesma e representar uma situação determinada. A resposta de Wittgenstein para esse problema está na chamada teoria afigurativa que afirma que uma proposição tem um sentido por ser uma figuração de situações da realidade. No Tractatus, todo o conteúdo representativo da linguagem repousa sobre as chamadas "proposições elementares". Segundo a teoria afigurativa, a proposição elementar pode representar fatos por ser, ela própria, um fato. Enquanto tal, ela é constituída por um arranjo de elementos mais simples que substituem ou se referem a objetos na realidade. Na medida em que têm o papel de se referir a um objeto, tais elementos são nomes e os objetos aos quais eles se referem são os seus significados. Deste modo, a proposição elementar representa a existência de um estado de coisas: que os seus nomes estejam uns para os outros de uma determinada maneira representa que os objetos, que eles substituem, assim estão uns para os outros no mundo. Se o estado de coisas afigurado é o caso na realidade, a proposição é verdadeira; se não é o caso, ela é falsa.

É ao oferecer uma teoria acerca da natureza essencial das nossas representações da realidade que Wittgenstein acaba por enunciar teses acerca das propriedades essenciais da realidade representada. Uma ideia central da obra é a de que a proposição, para ter um sentido, deve representar um estado de coisas possível. Isso significa que as possibilidades combinatórias que seus nomes possuem com outros nomes, em contextos proposicionais, devem espelhar as possibilidades combinatórias que os objetos, aos quais eles se referem, possuem com outros objetos em estados de coisas. No Tractatus, isso é o mesmo que dizer que a proposição deve ter sua forma lógica em comum com o estado de coisas afigurado. Linguagem e a realidade por ela representada seriam, portanto, domínios totalmente isomórficos. A linguagem consiste na totalidade das proposições elementares, cujas possibilidades de verdade e falsidade correspondem às possibilidades de existência e inexistência dos estados de coisas. Já a realidade é delimitada pelo espaço lógico que compreende a totalidade dos estados de coisas possíveis, dada a partir da totalidade dos objetos e suas possibilidades combinatórias.

\begin{tabular}{|c|c|l|l|c|c|}
\hline intuitio & $\begin{array}{c}\text { ISSN } \\
1983-4012\end{array}$ & Porto Alegre & Vol.7 - No.2 & $\begin{array}{c}\text { Novembro } \\
2014\end{array}$ & p. 51-72 \\
\hline
\end{tabular}


Há, pois, um perfeito espelhamento entre a totalidade das proposições elementares e a totalidade dos estados de coisas possíveis, e linguagem e realidade esgotam-se, respectivamente, nessas totalidades.

Até aqui, essa exposição da teoria tractariana da representação deu-se de maneira neutra com relação à polêmica entre as leituras realista e antirrealista. Mas, como foi dito acima, é peculiar de uma leitura realista a ideia de que as teses de Wittgenstein acerca das propriedades últimas da realidade dizem respeito a um domínio que seria anterior e independente da linguagem que a representa. Para entendermos melhor essa postura será útil tomar aquela que seria a mais significativa dentre essas teses: a de que os objetos, que atuam como os referentes dos nomes, são entidades simples que, por conta disso, subsistem independentemente do que seja o caso. Wittgenstein deduz esta tese a partir de sua investigação acerca da possibilidade do sentido proposicional, mas, tendo em vista os objetivos deste trabalho, não será necessário que eu me ocupe aqui com os detalhes dessa sua argumentação. O que importa frisar é que, em uma leitura realista, o espaço lógico, constituído pelos objetos simples e suas possibilidades combinatórias, é concebido como um domínio real anterior e independente da linguagem, com o qual esta teria que se conformar para poder representar. Nesse sentido, poder-se-ia dizer que essa linha interpretativa defende uma concepção realista dos objetos simples do Tractatus. Sendo assim, as possibilidades combinatórias dos objetos pertenceriam a eles de maneira totalmente intrínseca, de modo que, para que a linguagem seja possível, caberiam aos nomes "duplicá-las", incorporando-as nas possibilidades combinatórias que eles possuem com outros nomes em contextos proposicionais. Assim, lemos em Pears:

\begin{abstract}
A ideia é a de que, em todas as nossas operações com a linguagem, estamos seguindo em trilhos fixos estabelecidos na realidade antes de nós termos sequer aparecido em cena. Anexe um nome a um objeto e a natureza intrínseca do objeto irá imediatamente assumir o controle completo e determinar o uso correto do nome nas ocasiões posteriores ${ }^{2}$.
\end{abstract}

Como foi dito acima, o que leva Pears e outros intérpretes realistas a essa concepção do estatuto das teses de Wittgenstein, acerca das propriedades últimas da realidade, é a maneira pela qual eles entendem os mecanismos da teoria tractariana da linguagem. Eles sustentam que, no Tractatus, o contato entre linguagem e realidade se dá fundamentalmente a partir de correlações singulares e externas entre nomes e objetos. Ao qualificar tais correlações como singulares, quero dizer que elas envolveriam apenas dois elementos: um nome e um objeto. Trata-se, portanto, de uma ligação individual entre dois termos, que não faz qualquer referência a outros nomes ou a outros objetos além dos dois envolvidos. E tais correlações seriam externas porque elas devem ser entendidas como ligações que partem de um determinado domínio em direção a outro domínio externo ao primeiro.

\footnotetext{
${ }^{2}$ PEARS, D. F. The False Prison: A Study of the Development of Wittgenstein's Philosophy - Volume One. Nova York: Oxford University Press, 2004, p 10; grifo nosso; tradução nossa.

\begin{tabular}{|c|c|l|l|c|c|}
\hline intuitio & $\begin{array}{c}\text { ISSN } \\
1983-4012\end{array}$ & Porto Alegre & Vol.7- No.2 & $\begin{array}{c}\text { Novembro } \\
2014\end{array}$ & p. 51-72 \\
\hline
\end{tabular}
}


O apelo a tais correlações aparece claramente em Pears, que diz: "No Tractatus, o início da linguagem é a nomeação de objetos" " ${ }^{3}$. Segundo Pears, a teoria da linguagem do Tractatus pressupõe, portanto, a existência de atos de "nomeação". Na sua interpretação, o contato entre linguagem e realidade está fundamentalmente apoiado em tais atos. Como ele diz, esses atos seriam o "começo da linguagem", isto é, aquilo que estabelece, em primeiro lugar, a conexão entre os dois domínios. A passagem citada acima revela ainda que esses atos seriam correlações singulares entre nomes e objetos, no sentido que especificamos. Pois essa passagem diz que as relações formais que um nome manterá com outros nomes são consequência de sua anexação a um objeto: primeiro é anexado um nome a um objeto e, a partir daí, esse nome incorpora as possibilidades combinatórias do objeto nomeado. Uma vez que a correlação inicial entre um nome e um objeto seria o que dá origem às propriedades sintáticas dos nomes, a sintaxe da linguagem não poderia exercer qualquer papel no ato de nomeação. Este último consistiria, portanto, em uma correlação singular entre dois itens, no sentido de que ele não faria referência às relações sintáticas que o nome em questão possui com outros nomes. E tal correlação deve também ser entendida como externa, pois ela parte da linguagem em direção ao elemento constituinte de um domínio externo a essa última.

Penso não haver necessidade de discutirmos detalhadamente o modo como um apelo a correlações singulares e externas entre nomes e objetos aparece no trabalho de cada um dos intérpretes que poderíamos classificar como proponentes de uma leitura realista. De todo modo, penso que esse apelo pode ser encontrado, por exemplo, em Kenny, que, a partir de uma interpretação particular do aforismo 3.11, atribui o papel de realizar tais correlações especificamente ao pensamento: segundo Kenny, caberia ao pensamento estender "linhas projetivas" que conectariam os sinais simples da linguagem a objetos exteriores, de modo que arranjos de sinais, por si mesmos vazios e sem qualquer conteúdo significativo, passariam, então, a representar situações e a expressar um sentido ${ }^{4}$. Já Anscombe distingue duas características em uma proposição: primeiro, a relação entre seus elementos constituintes; segundo, a correlação desses elementos com objetos fora da figuração. Tomada por si mesma, essa primeira característica não seria suficiente para representar uma situação determinada, pois ela resultaria apenas em um "protótipo de figuração". Para que se chegue à representação de uma situação determinada, seriam necessárias correlações que Anscombe qualifica como "externas" e "individuais" entre os elementos constituintes da proposição e os objetos da realidade ${ }^{5}$ Penso que tanto as "linhas projetivas" de que fala Kenny como as correlações "externas" e "individuais" de que fala Anscombe podem ser entendidas como desempenhando um papel análogo ao dos "atos de nomeação" de Pears, que examinamos no parágrafo anterior. Em todos estes casos, o contato entre linguagem e realidade representada está fundamentalmente apoiado em correlações singulares entre

\footnotetext{
${ }^{3}$ PEARS, D. F. The False Prison: A Study of the Development of Wittgenstein's Philosophy - Volume One. Nova York: Oxford University Press, 2004, p. 9; tradução nossa.

${ }^{4}$ Cf. KENNY, A. Wittgenstein. Revised edition. Blackwell Publishing, 2006, p. 48.

${ }^{5}$ Cf. ANSCOMBE, G. E. M. An Introduction to Wittgenstein's Tractatus. 2. ed. Nova York: Harper \& Row, 1965, PP. 67-69.

\begin{tabular}{|c|c|l|l|c|c|}
\hline intuitio & $\begin{array}{c}\text { ISSN } \\
1983-4012\end{array}$ & Porto Alegre & Vol.7- No.2 & $\begin{array}{c}\text { Novembro } \\
2014\end{array}$ & p. 51-72 \\
\hline
\end{tabular}
}


nomes e objetos externos, de modo que é basicamente através delas que seria possível conferir sentidos determinados aos sinais da linguagem. Seguindo Pears, denominarei a máxima de que as conexões entre nomes e objetos possuem esse papel fundamental "princípio de representação"6.

Há certamente passagens, no Tractatus, que parecem favorecer o princípio de representação, assim entendido. Seguem-se as que penso ser as principais:

Um nome toma o lugar de uma coisa, um outro, o de outra coisa, e estão ligados entre si, e assim o todo representa - como um quadro vivo - o estado de coisas (4.0311).

A possibilidade da proposição repousa sobre o princípio da substituição [Vertretung] de objetos por sinais (4.0312).

A relação afiguradora consiste nas coordenações entre os elementos da figuração e as coisas.

Essas coordenações são como que as antenas dos elementos da figuração, com as quais ela toca a realidade (2.1514-2.1515).

Em 4.0311 e 4.0312, Wittgenstein parece estar dizendo explicitamente que os pontos de contato entre a proposição e o estado de coisas representado se estabelecem fundamentalmente a partir de relações de substituição (Vertretung) entre nomes e os objetos e que a própria possibilidade da proposição depende de tais relações. Em 2.1514-2.1515, Wittgenstein, com a noção de "coordenações entre os elementos da figuração e as coisas", parece estar postulando entre os mecanismos da linguagem algo análogo ao que viemos denominando correlações singulares e externas.

Como tenho insistido até aqui, é precisamente a partir desta interpretação acerca do modo pelo qual os sentidos proposicionais são determinados que estes intérpretes chegam àquelas que foram colocadas como as teses centrais de uma leitura realista do Tractatus. Essa linha de argumentação aparece de maneira bastante explícita em Norman Malcolm, que é mais um dos proponentes dessa linha interpretativa. Lemos em Malcolm: "O próprio Tractatus contém evidências que contam em favor da ideia de que 'objetos' são ontologicamente independentes de 'nomes" cita como evidência "em favor da tese de que objetos são ontologicamente independentes dos nomes" justamente os aforismos 4.0311 e 4.0312, os quais, como procurei mostrar, parecem estar dando ênfase ao chamado princípio de representação. Após citá-los, Malcolm conclui:

A insistência de Wittgenstein em dizer que um nome "é um substituto do", "toma o lugar de" um objeto deixa bastante claro que ele pensava em um objeto como algo totalmente separado da sintaxe de um nome [...]. Um nome toma o lugar de um objeto; mas o nome e o objeto são duas coisas diferentes. É verdade, em um sentido, que, se uma palavra toma o lugar de um objeto, trata-se de uma questão de qual tipo de papel lógico-sintático esta palavra desempenha no simbolismo. Mas, se uma palavra toma o lugar de um objeto, trata-se também de uma questão de se há um objeto cujo lugar ela possa tomar [...]. E quando nós consideramos a comparação de

\footnotetext{
${ }^{6}$ Cf. PEARS, D. F. The False Prison: A Study of the Development of Wittgenstein's Philosophy - Volume One. Nova York: Oxford University Press, 2004, pp. 73-74.

${ }^{7}$ MALCOLM, N. Nothing is Hidden: Wittgenstein's Criticism of His Early Thought, (Oxford: Blackwell), 1986, p. 34; tradução nossa.

\begin{tabular}{|c|c|l|l|c|c|}
\hline intuitio & ISSN & Porto Alegre & Vol.7 - No.2 & $\begin{array}{c}\text { Novembro } \\
2014\end{array}$ & p. 51-72 \\
\hline
\end{tabular}
}


uma proposição com um quadro vivo, é difícil duvidar que os 'objetos' tenham uma existência anterior e independente dos 'nomes' dos quais eles são substitutos ${ }^{8}$.

A ênfase de Malcolm aqui é na escolha, por parte de Wittgenstein, da palavra Vertretung em 4.032. Segundo Malcolm, se a possibilidade do sentido proposicional depende fundamentalmente de que um elemento do sinal proposicional "substitua" ou "tome o lugar" de um objeto, então a existência desse objeto deve ser anterior e independente do sentido das proposições nas quais seus nomes podem ocorrer. Sua ideia é a de que só podemos falar em uma substituição de um objeto por um sinal se, antes mesmo da ocorrência dessa substituição, o primeiro existir, isto é, se houver um objeto a ser substituído. Dito de outro modo, para Malcolm só é possível uma relação de substituição de um item por outro se o item a ser substituído tiver uma existência anterior e independente com relação ao item que o substitui. Sendo assim, ao afirmar que o estabelecimento do sentido das proposições se dá a partir das relações de substituição entre nomes e objetos, a teoria tractariana do sentido proposicional estaria pressupondo uma concepção realista dos objetos, tal como é defendido em uma leitura realista.

Uma linha de argumentação semelhante aparece em Pears, que diz:

"Se 'a possibilidade das proposições está apoiada no princípio de que objetos têm sinais como seus representantes', como pode a identidade dos objetos representados por esses sinais depender dos sentidos das proposições em que eles ocorrem?"?

Nessa passagem, Pears faz uma pergunta retórica justamente a fim de atacar a interpretação antirrealista, que será examinada na seção seguinte. Por ora, cumpre observar apenas que Pears se vale do, assim chamado, princípio de representação para recusar a ideia de que a existência e a identidade dos objetos seja de, alguma forma, determinada pela linguagem. A afirmação de Wittgenstein de que a possibilidade das proposições depende da substituição de objetos por sinais excluiria qualquer dependência que os objetos poderiam ter com relação à linguagem. Pois, segundo Pears, se as conexões entre nomes e objetos externos é o que torna possível, em primeiro lugar, a expressão de um sentido determinado, então não se pode dizer que a existência ou a identidade desses objetos sejam de alguma forma dependentes das proposições nas quais seus nomes podem ocorrer. Antes, os objetos é que tornam possível a existência das proposições, pois, de acordo com o princípio de representação, não há sentidos proposicionais anteriores à ocorrência de relações de substituição entre nomes e objetos externos. Logo depois disso, Pears concluirá que a teoria afigurativa da proposição, da maneira como é entendida por ele, implica na aceitação da tese realista de que os objetos impõem sua forma aos nomes ${ }^{10}$. Seu argumento parece ser semelhante ao de Malcolm, segundo o qual a ideia de que as relações de substituição entre nomes e objetos são o que possibilita a geração das proposições implica

\footnotetext{
${ }^{8}$ MALCOLM, N. Nothing is Hidden: Wittgenstein's Criticism of His Early Thought, (Oxford: Blackwell), 1986, p. 35; tradução nossa; grifo nosso na última sentença.

${ }^{9}$ PEARS, D. F. The False Prison: A Study of the Development of Wittgenstein's Philosophy - Volume One.

Nova York: Oxford University Press, 2004, p. 100; tradução nossa.

${ }^{10}$ Cf. PEARS, D. F. The False Prison: A Study of the Development of Wittgenstein's Philosophy - Volume One. Nova York: Oxford University Press, 2004, p. 111.

\begin{tabular}{|c|c|c|c|c|c|}
\hline intuitio & $\begin{array}{c}\text { ISSN } \\
1983-4012\end{array}$ & Porto Alegre & Vol.7 $-\mathrm{N}^{\circ} .2$ & $\begin{array}{c}\text { Novembro } \\
2014\end{array}$ & p. 51-72 \\
\hline
\end{tabular}
}


que esses objetos tenham uma existência anterior à ocorrência dessas relações. Disso, seguir-se-ia que os objetos é que "ditam" quais serão as possibilidades combinatórias dos nomes que os substituem, e que, de maneira geral, a rede fixa de objetos constitui um domínio real que impõe sua forma à linguagem que o representa.

\section{A leitura antirrealista apoiada na concepção de significado enquanto uso dos nomes em contextos proposicionais}

Como foi dito anteriormente, a leitura antirrealista caracteriza-se pela ideia de que as teses de Wittgenstein acerca das propriedades essenciais e imutáveis da realidade não dizem respeito a uma realidade concebida como anterior e independente da linguagem que a representa. Assim como ocorre na leitura rival, essa linha interpretativa tem como base uma determinada interpretação acerca do modo pelo qual, segundo o Tractatus, os sentidos proposicionais são estabelecidos, isto é, acerca do modo pelo qual é conferido um conteúdo significativo aos sinais da linguagem. Seus proponentes insistem que a teoria tractariana do sentido proposicional não inclui um apelo a correlações singulares e externas entre nomes e objetos. Segundo esses intérpretes, na teoria tractariana da linguagem o significado de um nome não consiste em uma entidade externa independente com a qual ele manteria uma relação de substituição em virtude da realização de tais correlações. Antes, a concepção tractariana de significado estaria, na verdade, ligada à noção do uso que os nomes possuem em contextos proposicionais em virtude da posição que eles ocupam no interior da sintaxe lógica da linguagem tomada como um todo. Expliquemos então essa posição assumida por eles.

Penso que, de modo geral, ela caracteriza-se por extrair todas as implicações do chamado princípio do contexto. Este princípio ganha sua expressão mais clara em 3.3, que diz: "Só a proposição tem sentido; é só no contexto da proposição que o nome tem significado". De acordo com essa linha interpretativa, está implícita no princípio do contexto, e em passagens relacionadas, a ideia de que, no Tractatus, a conexão do nome com seu significado deve ser entendida como algo dependente da ocorrência do primeiro em proposições com sentido. Por conseguinte, devemos entender a identificação do significado de um nome como um processo realizado no interior da linguagem, que consiste em atentar para o papel desempenhado pelo nome no contexto das proposições. Identificar o significado de um nome seria apreender a contribuição que esse nome dá para a caracterização do sentido das proposições em que ele pode ocorrer, e não correlacioná-lo individualmente com uma entidade exterior através de um ato que não faz referência aos seus contextos proposicionais possíveis.

A ideia de que a identificação do significado de um nome depende da apreensão de sua contribuição para o sentido das proposições em que ele pode ocorrer teria mostrado que o princípio do contexto, levado às últimas consequências, implica não só que um nome tem significado apenas no contexto de uma proposição, mas também que a apreensão de seu significado deve levar em consideração todo o sistema de representação ao qual esse nome pertence. Ou seja, é só no contexto da

\begin{tabular}{|c|c|l|l|c|c|}
\hline intuitio & $\begin{array}{c}\text { ISSN } \\
1983-4012\end{array}$ & Porto Alegre & Vol.7 - No.2 & $\begin{array}{c}\text { Novembro } \\
2014\end{array}$ & p. 51-72 \\
\hline
\end{tabular}


linguagem tomada como um todo que um nome tem significado. Pois, se a identificação do significado de um nome exige necessariamente a consideração da classe de todas proposições em que ele pode ocorrer, então cada nome, de certa forma, contém uma referência a todos os nomes da linguagem. A possibilidade da linguagem, no Tractatus, pressuporia que esteja dado de antemão todo o espaço lógico de combinações possíveis entre os nomes. Cada proposição ocupa uma posição determinada nesse espaço lógico e determinar o seu sentido é determinar essa sua posição. Sendo assim, a atribuição de significado aos sinais simples da linguagem deve ser entendida como um processo que pressupõe o domínio da linguagem tomada como um todo, pois um nome só é o nome que é, e a proposição só é a proposição que é, devido ao lugar determinado que eles ocupam no contexto de todo espaço lógico. Ao contrário do que sustenta Pears, pode-se dizer então que não são atribuições individuais de significados que, por assim dizer, "iniciam" a linguagem. Antes, é a linguagem, tomada como um todo, que possibilita que um nome tenha significado, pois seu significado define-se completamente pela posição determinada que esse nome ocupa no interior da linguagem.

Uma vez que o significado de um nome não é especificável independentemente das relações internas que ele mantém com a totalidade dos outros nomes da linguagem, seguir-se-ia que a identificação de seu significado deve se dar no interior da linguagem. Como diz McGinn, uma proponente desta linha interpretativa, apreender o significado de um nome é apreender sua contribuição para a determinação dos lugares lógicos das proposições em que ele pode ocorrer: “Apreender o significado de uma expressão é apreender a regra para o seu uso em proposições, isto é, apreender a contribuição que ela dá para a determinação de um lugar de uma figuração lógica no espaço lógico" "11. Como foi dito acima, o princípio do contexto implicaria que esse espaço lógico está dado de antemão. A identificação do significado de um nome seria, então, um processo realizado tão somente no interior do espaço lógico dado juntamente com o sistema de representação ao qual o nome pertence. Sendo assim, essa identificação seria completamente realizável no interior da linguagem, através da apreensão do modo como os nomes contribuem para a circunscrição de um lugar lógico determinado, e não através de supostas correlações não-contextuais com objetos externos à linguagem.

Mais uma vez, dispenso-me aqui da tarefa de um exame detalhado do modo como a concepção de que, no Tractatus, a identificação do significado dos nomes se dá por meio da apreensão de seu uso no interior da linguagem aparece no trabalho de cada um dos intérpretes que poderíamos classificar como proponentes de uma leitura antirrealista. Apenas indico que essa concepção pode ser encontrada em Ishiguro, quando ela, por exemplo, atribui ao Tractatus a tese de que a identidade do significado de um nome só pode ser estabelecida "pelo seu uso em um conjunto de proposições" ${ }^{12}$, e quando ela afirma: "No Tractatus, apreender o uso de um nome é apreender a identidade da referência do

\footnotetext{
${ }^{11}$ Elucidating the Tractatus - Wittgenstein's Early Philosophy of Logic and Language. Nova York: Oxford University Press, 2006, p. 132; tradução nossa.

${ }^{12}$ ISHIGURO, H. Use and Reference of Names. In: WINCH, P. (Org.) Studies in the Philosophy of Wittgenstein. Nova York: Routledge, 1969. pp. 20-21; tradução nossa.

\begin{tabular}{|c|c|l|l|c|c|}
\hline intuitio & $\begin{array}{c}\text { ISSN } \\
1983-4012\end{array}$ & Porto Alegre & Vol.7- No.2 & $\begin{array}{c}\text { Novembro } \\
2014\end{array}$ & p. 51-72 \\
\hline
\end{tabular}
}


Realidade e valores de verdade no Tractatus de Wittgenstein: uma defesa de uma concepção realista dos objetos

nome" ${ }^{, 13}$. E em McGuinness, quando ele recusa que os significados dos nomes possam ser localizados mediante uma "exploração da realidade", e afirma: "Já está contida na linguagem e no pensamento a possibilidade de todos os objetos possíveis. Todas as formas lógicas são logicamente possíveis no interior da linguagem, no interior do pensamento" ${ }^{\text {14 }}$. Em todos esses casos, temos a ideia de que o significado de um nome, no Tractatus, é estabelecido pelo seu uso e pela sua posição no interior da linguagem, e não por uma correlação singular, isto é, não-contextual, com um objeto externo.

Dito isso, cumpre mostrar agora de que maneira essa interpretação particular acerca da identificação dos significados dos nomes leva àquelas que foram colocadas como as teses centrais de uma leitura antirrealista do Tractatus, isto é, a rejeição de uma concepção realista dos objetos e, por conseguinte, da ideia de que o Tractatus contém teses acerca das propriedades essenciais de uma realidade independente da linguagem. Vimos que o exame da concepção tractariana de significado, implícita no princípio do contexto, quando este é levado às suas últimas consequências, teria mostrado que o significado de um nome se define essencialmente pela aplicação deste no interior da linguagem. Nesse caso, determinar o significado de um nome não seria ligá-lo individualmente a uma entidade externa e independente da linguagem, mas sim apreender o seu uso no interior de um sistema de representação onde geramos proposições com sentido. Como diz McGinn, isso mostra que, no Tractatus, a investigação acerca da noção de significado não é dirigida propriamente para $o$ que os sinais significam (isto é, uma suposta entidade externa independente), mas para como eles significam:

\begin{abstract}
"A transformação na abordagem de Wittgenstein acerca da clarificação do funcionamento da linguagem que é acarretada pelo seu entendimento do princípio do contexto é a de desviar nossa atenção de uma preocupação para com $o$ que os sinais significam e voltá-la em direção a como eles simbolizam". ${ }^{15}$
\end{abstract}

Wittgenstein estaria sustentando, então, que um nome tem significado na medida em que fazemos dele um uso no interior da linguagem, e não na medida em que ele substitui uma entidade exterior independentemente especificável.

Isso mostraria que a existência e a identidade dos objetos não precisam e nem podem ser pensadas como independentes da linguagem. E, de modo geral, toda a rede lógica de possibilidades dadas juntamente com os objetos simples e suas possibilidades combinatórias não poderia ser entendida como constituindo um domínio real independente. Se, no Tractatus, dizer que um nome significa não é dizer que o correlacionamos individualmente a uma entidade exterior, mas sim dizer que fazemos dele uma aplicação no interior da linguagem, então, segundo esses intérpretes, não se pode concluir que o significado dos nomes são entidades exteriores independentes dessa aplicação. A

\footnotetext{
${ }^{13}$ ISHIGURO, H. Use and Reference of Names. In: WINCH, P. (Org.) Studies in the Philosophy of Wittgenstein. Nova York: Routledge, 1969, p. 35; tradução nossa.

${ }^{14}$ McGUINNESS, B. F. The So-called Realism of the Tractatus. In: BLOCK, I. (Org.) Perspectives on the Philosophy of Wittgenstein. Cambridge, Massachusetts: M.I.T. Press, 1983. p. 70; tradução nossa.

${ }^{15}$ Elucidating the Tractatus - Wittgenstein's Early Philosophy of Logic and Language. Nova York: Oxford University Press, 2006, p. 167; tradução nossa.

\begin{tabular}{|c|c|l|l|c|c|}
\hline intuitio & $\begin{array}{c}\text { ISSN } \\
1983-4012\end{array}$ & Porto Alegre & Vol.7- No.2 & $\begin{array}{c}\text { Novembro } \\
2014\end{array}$ & p. 51-72 \\
\hline
\end{tabular}
}


existência e a identidade de objetos seriam completamente determinadas pelo uso dos nomes em contextos proposicionais, de modo que a postulação de sua existência seria apenas uma tese acerca da ordem lógica essencial dos nossos sistemas de representação. Por conseguinte, o correto seria abandonar uma concepção realista acerca deles: "Wittgenstein não está tentando deduzir algo acerca da realidade que está fora da linguagem, mas está tentando clarificar a ordem lógica que é essencial para qualquer sistema no qual estados de coisas possíveis são representados"16. Ou, como diria McGuinness, uma suposta concepção realista dos objetos seria "um tipo de mito ontológico que ele [Wittgenstein] quer nos oferecer para mostrar a natureza da linguagem"17 .

Porém, continua sendo indisputável que, segundo o Tractatus, a linguagem representa uma realidade. Sabemos que, no Tractatus, uma proposição é essencialmente a representação de uma situação e que é sobre sua capacidade representativa que repousa o seu sentido. Se o contato entre linguagem e realidade não se dá por meio de correlações singulares entre nomes e objetos externos, de que maneira, afinal, esse contato estabelecer-se-ia segundo essa linha interpretativa? A ideia de seus proponentes é a de que ele se dá na medida em que o valor de verdade das proposições é determinado pela existência e inexistência de situações na realidade. Em outras palavras, é o sentido da proposição, tomada como um todo, que a conecta com a realidade, e não correlações singulares entre seus nomes e objetos externos. A questão que se coloca então é a de saber em que medida essa linha interpretativa é capaz de explicar a possibilidade de que, para cada proposição, corresponda uma situação determinada cuja existência ou inexistência a verifica ou falsifica. Como foi dito na Introdução, isso não pode ser explicado, de modo que uma leitura antirrealista do Tractatus não é capaz de dar conta dos valores de verdade das proposições. Uma vez que, nessa linha interpretativa, o contato entre linguagem e realidade se dá a partir da conexão entre proposições e aquilo que a verifica ou falsifica, segue-se que ela não pode explicar a capacidade representativa da linguagem e que, por conseguinte, deve ser abandonada.

\section{Capacidade das leituras realista e antirrealista de explicar o sentido das proposições}

Antes, porém, de passar ao problema do valor de verdade das proposições, cumpre examinar em que medida essas leituras opostas dão conta de explicar a possibilidade da expressão de sentidos determinados. Vimos que ambas se baseiam em suas respectivas interpretações acerca do modo pelo qual, segundo o Tractatus, os sentidos proposicionais são estabelecidos. Por conseguinte, parece que uma boa maneira de avaliar qual é a leitura correta seria examinar se suas concepções acerca dos

\footnotetext{
${ }^{16}$ McGINN, M. Elucidating the Tractatus - Wittgenstein's Early Philosophy of Logic and Language. Nova York: Oxford University Press, 2006, p. 100; tradução nossa.

${ }^{17}$ McGUINNESS, B. F. The So-called Realism of the Tractatus. In: BLOCK, I. (Org.) Perspectives on the Philosophy of Wittgenstein. Cambridge, Massachusetts: M.I.T. Press, 1983. p. 63; tradução nossa; grifo nosso.

\begin{tabular}{|c|c|l|l|c|c|}
\hline intuitio & $\begin{array}{c}\text { ISSN } \\
1983-4012\end{array}$ & Porto Alegre & Vol.7- No.2 & $\begin{array}{c}\text { Novembro } \\
2014\end{array}$ & p. 51-72 \\
\hline
\end{tabular}
}


mecanismos envolvidos no estabelecimento dos sentidos funcionam enquanto interpretações da teoria tractariana do sentido proposicional e se elas encontram apoio textual.

Há, certamente, passagens no Tractatus que favorecem a ideia, pressuposta na leitura realista, de que os sentidos proposicionais são estabelecidos fundamentalmente mediante correlações singulares e externas entre nomes e objetos. Vimos acima que, em 2.1514-2.1515, Wittgenstein fala explicitamente em "relações afiguradoras" que consistiriam em "coordenações entre os elementos da figuração e as coisas". Tais relações seriam, aparentemente, precisamente o que tenho denominado correlações singulares e externas entre nomes e objetos. Além disso, que os sentidos proposicionais estejam fundamentalmente apoiados em tais correlações parece estar implícito em 4.0311-4.0312, onde Wittgenstein afirma que a possibilidade da proposição repousa sobre a substituição entre objetos e os sinais simples da linguagem. Por razões indicadas na seção 2 deste artigo, tais ideias, segundo os intérpretes realistas, levariam a uma concepção realista dos objetos e, por conseguinte, à tese de que o Tractatus contém teses acerca de uma realidade anterior e independente.

Por outro lado, à primeira vista parece haver um problema na ideia, pressuposta na leitura antirrealista, de que a identificação do significado de um nome se dá exclusivamente por meio de uma consideração, realizada no interior da linguagem, da classe de proposições em que ele pode ocorrer. Se essa consideração é suficiente para a identificação do significado de um nome, e o apelo a uma correlação singular com um objeto externo é excluído, essa interpretação parece implicar que a identificação do significado de um nome só pode levar em conta suas possibilidades combinatórias com outros nomes em proposições com sentido. No Tractatus, isso é o mesmo que dizer que essa identificação só pode levar em consideração a forma do nome. Isso porque a forma de um nome, assim entendida, parece ser tudo o que pode ser identificado através de uma consideração, realizada no interior da linguagem, da classe de proposições em que ele pode ocorrer. Nesse caso, a contribuição de um nome para a determinação do sentido de uma proposição seria unicamente a indicação de um lugar lógico-sintático. Porém, isso implicaria que, se dois nomes partilham de um mesmo conjunto de possibilidades combinatórias com outros nomes em proposições, não poderíamos individualizá-los de uma maneira totalmente precisa, nem distinguir um do outro sem certa ambiguidade.

Para entendermos em que consiste essa ambiguidade e por que ela parece ser implicada pela leitura antirrealista, vamos supor uma linguagem na qual temos dois nomes, $a$ e $b$, de mesma forma lógica. Isto é, $a$ e $b$ partilham de um mesmo conjunto de possibilidades combinatórias com outros nomes em proposições. Vamos supor também um determinado mundo, a ser descrito por essa linguagem, no qual apenas um desses nomes produz uma proposição verdadeira quando combinados em um contexto proposicional designado, por exemplo, por ' $f x$ '. Pode-se dizer então que o espaço lógico em questão prevê duas situações possíveis que são descritas por proposições que partilham de

\begin{tabular}{|c|c|l|l|c|c|}
\hline intuitio & $\begin{array}{c}\text { ISSN } \\
1983-4012\end{array}$ & Porto Alegre & Vol.7 - No.2 & $\begin{array}{c}\text { Novembro } \\
2014\end{array}$ & p. 51-72 \\
\hline
\end{tabular}


uma mesma forma lógica, $\varphi(x)^{18}$, mas uma dessas situações é o caso e a outra não. Porém, se sustentarmos que o significado dos nomes deve ser identificado exclusivamente com base em uma consideração realizada no interior da linguagem, e se $a$ e $b$ possuem a mesma forma lógica, poder-seia levantar a seguinte questão: é possível especificar se no mundo em questão a proposição " $f a . \sim f b$ " é verdadeira e " $f a . f b "$ é falsa; ou, se " $f a . f b "$ é verdadeira e " $f a . \sim f b "$ é falsa? Em outras palavras, podemos especificar qual proposição, $f a$ ou $f b$, é verificada pela situação que é o caso nesse mundo?

Penso que isso não pode ser especificado, de modo que essa linha interpretativa implica, sim, em uma ambiguidade desse tipo. Para entendermos o porquê disso, convém indicar o que parece ser a única maneira pela qual ela poderia ser resolvida. Ela pode ser desfeita se for admitida a possibilidade de correlações singulares entre sinais e objetos externos. Tais correlações se estabeleceriam, ponto a ponto, entre o sinal " $a$ " e um objeto determinado, e entre o sinal " $b$ " e um outro objeto determinado. Tais objetos possuiriam uma mesma forma, mas, por meio dessas correlações, poderíamos especificar qual objeto é nomeado por ' $a$ ' e qual é nomeado por ' $b$ '. Assim, é possível dizer, por exemplo, que " $f a . \sim f b$ " expressa uma proposição verdadeira e " $f a . f b$ " expressa uma proposição falsa, pois " $a$ " teria sido correlacionado com um objeto que possui certas ligações efetivas com outros objetos, abreviados em " $f x$ ", ao passo que " $b$ " foi correlacionado com um outro objeto que não possui tais ligações. Deste modo, poder-se-ia dizer que no mundo em questão " $f a . \sim f b$ " é verdadeira, e não " $f a . f b$ ".

Porém, não vejo de que maneira isso pode ser realizado em uma leitura antirrealista. Ao afirmarem que o significado de um nome é identificável no interior da linguagem, os proponentes dessa linha interpretativa se comprometem com a tese de que o único critério disponível para a identificação do significado dos nomes é sua forma lógica. Isso porque não poderia existir um outro meio de discriminação dos nomes além da identificação de suas respectivas categorias lógicosintáticas. Exigir outro meio de discriminação seria abandonar a tese de que o significado de um nome é completamente identificável no interior da linguagem. Sendo assim, quando eles dizem que apreender o significado de um nome é apreender a contribuição que ele dá para a determinação de um lugar lógico, eles só podem estar dizendo que apreender seu significado é apreender sua posição na estrutura sintática da linguagem. Se $a$ e $b$ possuem a mesma forma lógica, a única maneira de distinguir um do outro seria correlacioná-los individualmente a entidades externas para, deste modo, especificar que " $a$ " designa este objeto e " $b$ " designa este outro. Porém, sabemos que é essencial para essa linha interpretativa o abandono de um apelo a tais correlações.

Essas implicações da leitura antirrealista são vistas como problemáticas por alguns intérpretes realistas. David Pears, por exemplo, afirma que descrições do mundo nas quais não foi realizado algo equivalente a correlações singulares e externas seriam incompletas. Com isso, ele sugere que tais descrições devem ser suplementadas com algo que fixe os referentes dos nomes de uma maneira mais

18 " $\varphi x "$ atua aqui como uma proposição na qual todas as suas partes foram substituídas por variáveis. " $\varphi$ " atua aqui como uma variável que substitui o contexto proposicional indicado acima por " $f$ ", e " $x$ " atua como uma variável cujos possíveis valores são " $a$ " e " $b$ ".

\begin{tabular}{|c|c|l|l|c|c|}
\hline intuitio & $\begin{array}{c}\text { ISSN } \\
1983-4012\end{array}$ & Porto Alegre & Vol.7 - No.2 & $\begin{array}{c}\text { Novembro } \\
2014\end{array}$ & p. 51-72 \\
\hline
\end{tabular}


determinada ${ }^{19}$. No entanto, há uma passagem no Tractatus que parece afirmar explicitamente que tais suplementações não são necessárias. Trata-se do aforismo 5.526, que diz:

Pode-se descrever integralmente o mundo por meio de proposições completamente generalizadas, ou seja, sem que nenhum nome seja de antemão coordenado a um objeto determinado.

Para se chegar, então, ao modo habitual de expressão, deve-se, após uma expressão: "há um único $x$ tal que...", simplesmente dizer: e esse $x$ é $a$.

Uma descrição completamente generalizada do mundo seria uma descrição que emprega unicamente variáveis. Tratar-se-ia, portanto, daquilo que Wittgenstein denomina "protótipo lógico de figuração". Um protótipo lógico expressa, através do uso de variáveis, uma forma lógica (cf. 3.315). Ao afirmar que o mundo pode ser descrito integralmente através de protótipos lógicos de figuração, Wittgenstein estaria sustentando que a apreensão do conteúdo significativo de qualquer proposição leva em consideração unicamente aquilo que pode ser expresso através da aplicação lógico-sintática das variáveis no contexto de um protótipo lógico. Em outras palavras, o sentido de qualquer proposição deve ser apreendido exclusivamente através da identificação das propriedades formais das expressões nela contidas. Portanto, uma descrição puramente formal de uma situação não careceria de qualquer suplementação, isto é, não precisaria ser complementada com supostas correlações singulares que associariam cada variável a um objeto externo determinado. Poder-se-ia dizer que tudo o que há de relevante na expressão de sentidos determinados deve poder ser apreendido através de mecanismos puramente formais, de modo que a identificação do significado dos nomes se daria exclusivamente no interior da linguagem. Por conseguinte, a implicação de que a identificação do significado de um nome só pode levar em consideração sua forma lógica não constituiria um obstáculo para a leitura antirrealista. Aliás, essa implicação seria, inclusive, algo favorável a essa leitura, pois com base no que lemos, em 5.526, podemos dizer que essa linha interpretativa pode dar conta, mais do que a leitura rival, da afirmação de Wittgenstein de que o mundo pode ser integralmente descrito por proposições completamente generalizadas. Pois, ao afirmá-lo, Wittgenstein estaria justamente excluindo que correlações singulares e externas entre nomes objetos estejam envolvidas entre os mecanismos de determinação de sentidos proposicionais, e assumindo que a linguagem possui as ambiguidades que decorrem disso. Por conta disso, Ishiguro cita 5.526 em favor de sua interpretação ${ }^{20}$, juntamente com passagens relacionadas ao chamado princípio do contexto, que foi examinado na seção anterior.

\footnotetext{
${ }^{19}$ PEARS, D. F. The False Prison: A Study of the Development of Wittgenstein's Philosophy - Volume One. Nova York: Oxford University Press, 2004, pp. 100-101, 113.

${ }^{20}$ ISHIGURO, H. The So-called Picture Theory: Language and the World, In. GLOCK, H. J. (ed.) Wittgenstein: A Critical Reader, Blackwell, Oxford, 2001. pp. 35-36.

\begin{tabular}{|c|c|l|l|c|c|}
\hline intuitio & $\begin{array}{c}\text { ISSN } \\
1983-4012\end{array}$ & Porto Alegre & Vol.7 - N . .2 & $\begin{array}{c}\text { Novembro } \\
2014\end{array}$ & p. 51-72 \\
\hline
\end{tabular}
}




\section{A impossibilidade de se explicar os valores de verdade das proposições em uma leitura antirrealista do Tractatus}

Vimos que é sobre suas respectivas interpretações acerca dos mecanismos de determinação do sentido proposicional que as leituras realista e antirrealista fundamentam suas ideias centrais de que o Tractatus contém e de que ele não contém uma concepção realista dos objetos, respectivamente. E vimos também que ambas as interpretações acerca dos mecanismos de determinação do sentido proposicional parecem encontrar apoio textual no Tractatus. Contudo, quero defender aqui que a questão de se o Tractatus contém, ou não, uma concepção realista dos objetos pode ser respondida independentemente de qual concepção acerca dos mecanismos de determinação do sentido proposicional é a correta. Isso porque, segundo penso, apenas se admitirmos, juntamente com os intérpretes realistas, que o Tractatus contém uma concepção realista dos objetos é possível explicar a possibilidade de um valor de verdade para as proposições.

É admitido pelos proponentes de ambas as leituras que o Tractatus defende o que podemos denominar uma "teoria da verdade por correspondência". No Tractatus, proposições são funções de verdade de proposições elementares, e o valor de verdade de uma proposição elementar é explicado a partir de uma noção de "existência" ou "inexistência" de algo em um domínio exterior com o qual ela é comparada. Este "algo" é o estado de coisas que corresponde à proposição na medida em que ele é representado por ela. Que o Tractatus possua tal concepção acerca dos valores de verdade pode ser constatado nas seguintes passagens, e não há outras passagens que pareçam sugerir o contrário:

2.21 A figuração concorda ou não com a realidade; é correta ou incorreta, verdadeira ou falsa.

$2.222 \mathrm{Na}$ concordância ou discordância de seu sentido com a realidade consiste sua verdade ou falsidade.

2.223 Para reconhecer se a figuração é verdadeira ou falsa, devemos compará-la com a realidade.

4.3 As possibilidades de verdade das proposições elementares significam as possibilidades de existência e inexistência dos estados de coisas.

Por conta dessa concepção acerca dos valores de verdade, os proponentes da leitura antirrealista, apesar de negarem que o Tractatus contenha uma concepção realista dos objetos e teses acerca das propriedades essenciais e imutáveis de uma realidade concebida como independente da linguagem, são levados a admitir que a teoria tractariana, ainda assim, pressupõe a existência de um domínio real exterior e independente da linguagem. Admiti-lo é necessário para que se possa explicar os valores de verdade das proposições. Wittgenstein afirma explicitamente que valores de verdade não podem ser determinados internamente à linguagem, mas que eles são impostos à linguagem por um domínio real no qual se dá a existência e a inexistência de estados de coisas. Tal domínio, por conseguinte, deve ter uma certa independência com relação à linguagem, isto é, que tais e tais estados de coisas sejam o caso e que tais e tais estados de coisas não sejam o caso não pode depender das propriedades internas do simbolismo. Do contrário, não haveria sentido em insistir na necessidade de

\begin{tabular}{|c|c|l|l|c|c|}
\hline intuitio & $\begin{array}{c}\text { ISSN } \\
1983-4012\end{array}$ & Porto Alegre & Vol.7 - No.2 & $\begin{array}{c}\text { Novembro } \\
2014\end{array}$ & p. 51-72 \\
\hline
\end{tabular}


uma comparação com um domínio real exterior à linguagem. Tais consequências da concepção tractariana acerca dos valores de verdade são admitidas pelos proponentes da leitura antirrealista, como Ishiguro: "A teoria afigurativa é uma teoria de interpretação de um mundo que está lá para ser comparado com o que nós pensamos e dizemos. Nós não construímos ou inventamos o mundo no qual nos encontramos [...]"21. E McGinn: "O sujeito [isto é, o usuário da linguagem] não cria o mundo: a questão de quais estados de coisas existem ou não existem é independente do sujeito e estabelecida apenas a posteriori”, 22 .

Ora, se esses intérpretes admitem que a teoria tractariana pressupõe um domínio real exterior e independente da linguagem, por que não admitir de uma vez que o Tractatus contém teses acerca das propriedades essenciais e imutáveis desse domínio? A resposta para isso é que, para eles, o contato entre linguagem e esse domínio real não se dá fundamentalmente através de conexões singulares entre nomes e objetos, mas, antes, através do sentido das proposições tomadas como um todo ${ }^{23}$. Nesse caso, a única contribuição da realidade, tomada como algo independente da linguagem, seria, por assim dizer, dizer "sim" ou "não" ao que é expresso pelas proposições, isto é, concordar ou discordar com elas. Todas as propriedades essenciais e imutáveis que Wittgenstein atribui à realidade pertenceriam a ela apenas na medida em que a estrutura essencial das proposições (que são articulações de nomes indefiníveis) é necessariamente preservada nas situações que as verificam ou falsificam. Diz McGinn: "O que nós tomamos como sendo metafísica [uma metafísica realista] é agora visto como sendo nada mais que uma questão de reconhecer que a ordem lógica essencial do nosso sistema de representação do mundo em proposições é essencialmente preservada na ordem lógica da realidade afigurada" ${ }^{24}$. Em suma, para cada proposição gerada a partir do uso dos nomes no interior da linguagem deve corresponder uma situação cuja existência ou inexistência a verifica ou falsifica. Porém, a forma lógica dessa situação não pertenceria a ela independentemente da linguagem, mas apenas na medida em que ela é representada por esta última.

É curioso que, de modo geral, esses intérpretes não tomam como algo problemático a possibilidade da conexão entre linguagem e realidade entendida da maneira indicada acima. Contudo, quero defender aqui que, no Tractatus, o contato entre a linguagem, entendida como a totalidade de proposições elementares constituídas por uma articulação de nomes indefiníveis, e o domínio real que confere valores de verdade às proposições só pode ser explicado se este último for por si mesmo (isto é, independentemente da linguagem que o representa) isomórfico à linguagem, isto é, se ele for por si mesmo constituído de objetos simples que subsistem independentemente do que seja o caso.

\footnotetext{
${ }^{21}$ ISHIGURO, H. The So-called Picture Theory: Language and the World, In. GLOCK, H. J. (ed.) Wittgenstein: A Critical Reader, Blackwell, Oxford, 2001. p. 44; tradução nossa.

${ }^{22}$ McGINN, M. Elucidating the Tractatus - Wittgenstein's Early Philosophy of Logic and Language. Nova York: Oxford University Press, 2006, p. 273; tradução nossa.

${ }^{23}$ Cf. ISHIGURO, H. The So-called Picture Theory: Language and the World, In. GLOCK, H. J. (ed.) Wittgenstein: A Critical Reader, Blackwell, Oxford, 2001, p. 36.

${ }^{24}$ McGINN, M. Elucidating the Tractatus - Wittgenstein's Early Philosophy of Logic and Language. Nova York: Oxford University Press, 2006, p. 143; tradução nossa; grifo nosso.

\begin{tabular}{|c|c|l|l|c|c|}
\hline intuitio & $\begin{array}{c}\text { ISSN } \\
1983-4012\end{array}$ & Porto Alegre & Vol.7- No.2 & $\begin{array}{c}\text { Novembro } \\
2014\end{array}$ & p. 51-72 \\
\hline
\end{tabular}
}


Primeiramente, cumpre observar que é indisputável que, no Tractatus, a rede lógica de possibilidades dadas juntamente com a totalidade dos nomes e a totalidade de proposições elementares constituídas por eles seja algo fixo e imutável. Wittgenstein deixa claro que, para ele, os sentidos das proposições não podem jamais depender de algo contingente. Do contrário, a linguagem não seria possível (cf. 2.021-2.0212). No Tractatus, isso é o mesmo que dizer que os significados dos nomes, que constituem as proposições, não dependem de nada contingente, mas são fixos e dados a priori. A diferença entre as duas linhas interpretativas seria, então, a de que, em uma leitura antirrealista, o espaço lógico de possibilidades constituído pelos objetos simples seria apenas um mero reflexo dessa rede lógica de possibilidades fixa e imutável constituída pelos nomes, enquanto que, em uma leitura realista, os objetos constituiriam um domínio real independente da linguagem que o representa.

Penso ser importante levantar, então, a seguinte questão: se, no Tractatus, a rede lógica de possibilidades fixa e imutável dada juntamente com a totalidade dos nomes é projetada sobre um domínio real que não é por si mesmo (isto é, independentemente da linguagem que o representa) isomórfico à linguagem (isto é, que não é constituído por objetos simples aos quais os nomes se referem), é possível garantir que para cada proposição elementar corresponda, nesse domínio real, uma situação cuja existência ou inexistência a verifica ou falsifica? Embora os proponentes da leitura antirrealista pareçam admitir essa possibilidade sem maiores problemas, acredito que a resposta para essa questão deve ser negativa. Tomemos, como exemplo, uma suposta proposição elementar composta por quatro nomes indefiníveis: “ $a b c d$ ”. É indisputável que, segundo o Tractatus, a essa proposição deve necessariamente corresponder uma situação possível, cuja existência ou inexistência a verifica ou falsifica. Como diz Wittgenstein: "A figuração contém a possibilidade da situação que ela representa" (2.203). Ora, em uma leitura realista a correspondência necessária entre "abcd" e uma situação possível do domínio que confere valores de verdade às proposições pode facilmente ser explicada. Esse domínio seria, ele próprio, constituído de objetos simples que correspondem, um a um, aos nomes da linguagem. Sendo assim, a correspondência entre " $a b c d$ " e aquilo que a verifica ou falsifica é explicada pelo fato de que os nomes dessa proposição substituem objetos determinados. Tais objetos, por serem simples, subsistem independentemente do que seja o caso. Por conseguinte, " $a b c d$ " expressa um sentido independentemente do que seja o caso, tal como é exigido pela teoria tractariana da linguagem. Mas, uma vez que tais objetos pertenceriam a um domínio que deve estar em posição de conferir valores de verdade às proposições, deve-se admitir que a existência e a identidade deles têm uma certa independência com relação à linguagem. Por conseguinte, teríamos o que venho denominando aqui uma concepção realista dos objetos, e as teses de Wittgenstein acerca deles tratarse-iam de teses acerca de um domínio real independente.

Contudo, se negarmos, como faz uma leitura antirrealista, que o domínio real independente que confere valores de verdade às proposições seja, por si mesmo, constituído de objetos simples, não se pode explicar nem garantir a conexão necessária entre proposições elementares e as possibilidades

\begin{tabular}{|c|c|l|l|c|c|}
\hline intuitio & $\begin{array}{c}\text { ISSN } \\
1983-4012\end{array}$ & Porto Alegre & Vol.7 - No.2 & $\begin{array}{c}\text { Novembro } \\
2014\end{array}$ & p. 51-72 \\
\hline
\end{tabular}


de existência e inexistência que as verificam e as falsificam. Se a rede de possibilidades fixa e imutável dada com a totalidade dos nomes fosse projetada sobre um domínio que não é, por si mesmo, isomórfico à linguagem, seria totalmente arbitrário tomar uma situação qualquer desse domínio e dizer que é precisamente ela a situação cuja existência ou inexistência verifica ou falsifica, por exemplo, a proposição " $a b c d$ ": a conexão entre a proposição e a porção da realidade que a verifica ou falsifica não poderia ser explicada. A rede lógica de possibilidades dada juntamente com a totalidade dos nomes formaria um véu intransponível, e não poderíamos dizer que a linguagem representa uma realidade.

Só se pode dizer justificadamente que uma proposição, como " $a b c d$ ", é verificada por uma situação determinada se houver algum vínculo ou conexão entre estes dois itens. Do contrário, seria totalmente arbitrário dizer que " $a b c d$ " é verificada pela existência desta situação, e não pela existência de uma outra situação qualquer. Mas, se os proponentes da leitura antirrealista negam que essa conexão seja estabelecida por relações de substituição (Vertretung) entre nomes e objetos externos, como explicar essa conexão, afinal? E, de modo geral, como se pode explicar e garantir que para cada região da rede de possibilidades dada juntamente com totalidade dos nomes indefiníveis corresponda necessariamente, e de maneira não-arbitrária, uma situação determinada cuja existência ou inexistência a verifica ou a falsifica? Uma resposta satisfatória para essa questão não é oferecida pelos proponentes da leitura antirrealista e não acredito que essa resposta seja possível. Pois não vejo de que maneira isso pode ser explicado no Tractatus a não ser que se admita, como ocorre em uma leitura realista, um isomorfismo entre essa rede de possibilidades dada com a totalidade dos nomes e o domínio real independente que confere valores de verdade às proposições. Apenas assim se pode explicar o contato, ou, por assim dizer, o "encaixe", entre a linguagem e tal domínio. Ora, mas sabemos que, no Tractatus, os sentidos proposicionais não podem ser contingentes, de modo que a rede de possibilidades dada com a totalidade dos nomes indefiníveis deve ser necessária, fixa e imutável. Se deve existir um isomorfismo entre essa rede de possibilidades e o domínio real que confere valores de verdade às proposições para que se possa garantir a conexão entre eles, parece-me inevitável a conclusão de que esse domínio real tenha, ele próprio, uma estrutura necessária, fixa e imutável. No Tractatus, isso é o mesmo que dizer que ele deve ser constituído por objetos simples que subsistem independentemente do que seja o caso e que possuem possibilidades combinatórias intrínsecas e imutáveis com outros objetos em estados de coisas. Apenas desse modo pode-se dizer justificadamente que uma determinada proposição elementar, entendida como uma concatenação de nomes indefiníveis, é verdadeira ou falsa devido à existência ou inexistência de algo totalmente determinado e que mantém com ela uma conexão essencial e não-arbitrária: a saber, uma "ligação de objetos simples" aos quais seus nomes se referem. Mas, vimos que, para que tais objetos estejam em posição de constituir um domínio que confere valores de verdade às proposições, eles devem possuir uma independência com relação à linguagem, pois a questão de quais estados de coisas são ou não o caso não pode depender das propriedades internas do simbolismo. Por conseguinte, as teses de Wittgenstein que

\begin{tabular}{|c|c|l|l|c|c|}
\hline intuitio & $\begin{array}{c}\text { ISSN } \\
1983-4012\end{array}$ & Porto Alegre & Vol.7 - No.2 & $\begin{array}{c}\text { Novembro } \\
2014\end{array}$ & p. 51-72 \\
\hline
\end{tabular}


postulam a existência de tais objetos são teses acerca de um domínio real independente, e não dizem respeito a um mero reflexo da ordem lógica dos nossos sistemas de representação imposta, pela linguagem, à realidade representada.

\section{Considerações finais}

Neste artigo, vimos que as leituras realista e antirrealista baseiam suas interpretações acerca do estatuto das teses tractarianas que tratam das propriedades últimas da realidade em suas respectivas concepções acerca dos mecanismos de determinação do sentido proposicional. Procurei mostrar, então, que essas duas concepções acerca dos mecanismos de determinação do sentido proposicional encontram algum apoio textual, mas que a resposta para a questão de se o Tractatus possui, ou não, uma concepção realista dos objetos não depende de qual dessas concepções é a correta. Pois, apenas se admitirmos que o espaço lógico constituído pelos objetos simples e suas possibilidades combinatórias possui uma independência com relação à linguagem é possível explicar o valor de verdade das proposições. Ao negarem essa independência, os proponentes da leitura antirrealista não são capazes de explicar o contato, ou, por assim dizer, o "encaixe", entre a linguagem e o domínio real independente que confere valores de verdade às proposições.

Contudo, gostaria de observar que, ainda que minha análise esteja correta e que, por conseguinte, a leitura realista seja a interpretação correta do Tractatus, disso não se seguiria que a concepção dos intérpretes realistas examinada aqui acerca dos mecanismos de determinação do sentido proposicional esteja de fato presente na obra. Pois, mesmo admitindo que o domínio real constituído pelos objetos simples tenha uma independência com relação à linguagem, não está excluída, a princípio, a possibilidade de que a identificação do significado dos nomes seja estabelecida no interior da linguagem, e não por correlações singulares e externas entre nomes e objetos. Nesse caso, os objetos formariam um sistema de referência exterior e independente da linguagem, que, contudo, seria mapeado no interior desta, por mecanismos puramente formais ${ }^{25}$. A questão de qual concepção acerca dos mecanismos de determinação do sentido proposicional é a interpretação correta do Tractatus é, sem dúvidas, de grande importância, mas ultrapassa os limites e objetivos deste artigo. Penso ter cumprido meu objetivo se tiver ajudado a mostrar que essa questão não é indispensável para a conclusão de que o Tractatus contém, de fato, uma concepção realista dos objetos e, por conseguinte, teses acerca de um domínio real independente.

Para concluir, gostaria de fazer uma observação final acerca dessa "independência" dos objetos com relação à linguagem, sobre a qual insisti ao longo de toda essa exposição. Pode-se dizer que, com base em certas passagens do Tractatus, o correto seria admitir que essa independência não

${ }^{25}$ Cf. MARQUES, J. O. A. Forma e Representação no Tractatus de Wittgenstein. Tese (Doutorado em Filosofia) - UNICAMP. Campinas. 1998. pp. 180-211. Disponível em http://www.bibliotecadigital.unicamp.br/document/?code=vtls000183508\&fd=y. Acessado em: 30/05/2014.

\begin{tabular}{|c|c|c|c|c|c|}
\hline intuitio & $\begin{array}{c}\text { ISSN } \\
1983-4012\end{array}$ & Porto Alegre & Vol.7 - No.2 & $\begin{array}{c}\text { Novembro } \\
2014\end{array}$ & p. 51-72 \\
\hline
\end{tabular}


seria absoluta, mas teria que ser relativizada. Falo das passagens em que Wittgenstein fala da "verdade" que ele julga existir no solipsismo, que consistiria em que os limites da minha linguagem são os limites do meu mundo (cf. 5.6-5.641). Este é, certamente, um tema de imensa complexidade, e um tratamento aprofundado acerca dele extrapolaria os limites e a intenção deste trabalho. De todo modo, gostaria de finalizar com duas considerações acerca deste ponto. Em primeiro lugar, seja qual for a interpretação correta dessas passagens, penso ter mostrado que, se a análise desenvolvida, neste trabalho, estiver correta, existiria, sim, um sentido em que teríamos que afirmar que os objetos têm uma independência com relação à linguagem. Isso porque eles constituiriam e fariam parte do domínio que impõe valores de verdade às proposições, e, como procurei mostrar acima, tal domínio, na medida em que desempenha este papel, deve ter uma certa independência com relação à linguagem. Em segundo lugar, apesar de não ter desenvolvido uma interpretação positiva acerca das passagens referentes ao solipsismo do Tractatus, penso que, se minha análise estiver correta, terei mostrado ao menos como essas passagens não devem ser interpretadas. A saber, identificação entre "os limites da minha linguagem" e "os limites do meu mundo", feita por Wittgenstein, não deve ser entendida como uma decorrência do fato de que a linguagem impõe sua forma ao mundo, na medida em que a existência e a identidade dos objetos seriam determinadas pelo uso dos nomes no interior da linguagem ${ }^{26}$. Vimos que, nesse cenário, os valores de verdade das proposições e, por conseguinte, o contato entre linguagem e realidade não poderiam ser explicados. Não seria possível dizer, então, que a linguagem representa uma realidade, o que seria um absurdo, visto que, no Tractatus, a essência da linguagem é ser uma representação de um domínio real exterior.

\section{Referências}

ANSCOMBE, G. E. M. An Introduction to Wittgenstein's Tractatus. 2. ed. Nova York: Harper \& Row, 1965. ISHIGURO, H. The So-called Picture Theory: Language and the World, In. GLOCK, H. J. (ed.) Wittgenstein: A Critical Reader. Oxford: Blackwell. 2001, pp. 27-46.

KENNY, A. Wittgenstein. Revised edition. Blackwell Publishing, 2006.

MALCOLM, N. Nothing is Hidden: Wittgenstein's Criticism of His Early Thought. Oxford: Blackwell. 1986. MARQUES, J. O. A. Forma e Representação no Tractatus de Wittgenstein. Tese (Doutorado em Filosofia). UNICAMP. $\quad$ Campinas. $1998 . \quad$ Disponível em http://www.bibliotecadigital.unicamp.br/document/?code=vtls000183508\&fd=y. Acessado em: 30/05/2014.

McGINN, M. Elucidating the Tractatus - Wittgenstein's Early Philosophy of Logic and Language. Nova York: Oxford University Press, 2006.

McGUINNESS, B. F. The So-called Realism of the Tractatus. In: BLOCK, I. (Org.) Perspectives on the Philosophy of Wittgenstein. Cambridge, Massachusetts: M.I.T. Press, 1983, pp. 60-73.

PEARS, D. F. The False Prison: A Study of the Development of Wittgenstein's Philosophy - Volume One. Nova York: Oxford University Press, 2004.

${ }^{26}$ Uma interpretação nessa linha acerca do solipsismo do Tractatus parece estar presente em McGinn (cf. McGINN, M. Elucidating the Tractatus - Wittgenstein's Early Philosophy of Logic and Language. Nova York: Oxford University Press, 2006, pp. 255-303); e em Ishiguro (Cf. ISHIGURO, H. The So-called Picture Theory: Language and the World, In. GLOCK, H. J. (ed.) Wittgenstein: A Critical Reader. Oxford: Blackwell. 2001, p. 44).

\begin{tabular}{|c|c|l|l|c|c|}
\hline intuitio & $\begin{array}{c}\text { ISSN } \\
1983-4012\end{array}$ & Porto Alegre & Vol.7 - No.2 & $\begin{array}{c}\text { Novembro } \\
2014\end{array}$ & p. 51-72 \\
\hline
\end{tabular}


Realidade e valores de verdade no Tractatus de Wittgenstein: uma defesa de uma concepção realista dos objetos

WITTGENSTEIN, L. Tractatus Logico-Philosophicus. Trad., notas e ensaio introdutório de Luiz Henrique Lopes dos Santos. 3. ed. São Paulo: Edusp, 2001.

Recebido em: 30/05/2014

Aprovado para publicação em: 06/08/2014 